Cite this: RSC Advances, 2013, 3, 18202

Received 29th April 2013,

Accepted 4th July 2013

DOI: $10.1039 / \mathrm{c} 3 \mathrm{ra} 42112 \mathrm{k}$

www.rsc.org/advances

\title{
Multi-parametric reference nanomaterials for toxicology: state of the art, future challenges and potential candidates
}

\author{
Guillermo Orts-Gil,†* Kishore Natte and Werner Österle
}

\begin{abstract}
A major requirement for the validation of methods assessing the risk associated with engineered nanoparticles (ENPs) is the use of reference materials (RMs). In the present contribution we review available RMs, ongoing projects and characterisation trends in the field. The conclusion is that actual approaches to RMs mostly deal with metrological considerations about single properties of the ENPs, typically their primary size, which can hardly be representative of nanoparticles characteristics in real testing media and therefore, not valid for reliable and comparable toxicological studies. As an alternative, we discussed the convenience and feasibility of establishing multi-parametric RMs for a series of ENPs, focusing on silica nanoparticles (SNPs). As a future perspective, the need to develop RMs based on hybrid nanoparticles is also discussed.
\end{abstract}

\section{Introduction}

Although nanoparticles, objects with at least one dimension $<100 \mathrm{~nm}$, have always been present in nature, only after refining analytical techniques, e.g. electron microscopy, have they become "visible" to scientists. ${ }^{1}$ Simultaneous to the development of synthetic methods to produce engineered

Federal Institute for Materials Research and Testing (BAM), Unter den Eichen 87, D12205 Berlin, Germany. E-mail: guillermo.orts-gil@mpikg.mpg.de

$\dagger$ Present address: Max Planck Institute of Colloids and Interfaces (MPIKG), Arnimallee 22, D-14195 Berlin, Germany. nanoparticles (ENPs) on a large scale ${ }^{2-4}$ considerations about their potential risk for human health and impact on environment are an object of concern. ${ }^{5}$

In general, the commercial use of materials has been traditionally accepted as safe, unless scientific evidence proves their harm. Nevertheless, this conception has gradually changed in the last years and the "precautionary principle" (the absence of knowledge about the dangers is taken as not safe) will probably play a major role also in the future of nanotechnology.

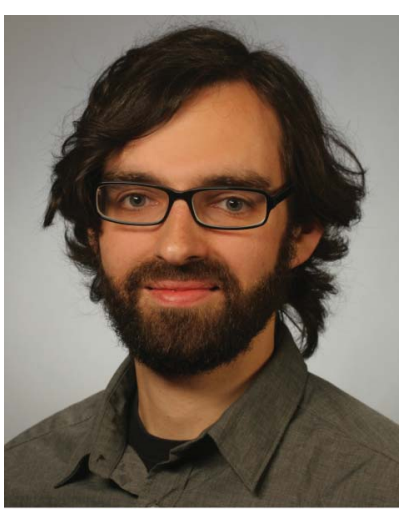

Guillermo Orts-Gil
Guillermo Orts-Gil is principal investigator and coordinator of the group of Nanoparticles and Colloidal Polymers of Professor Peter H. Seeberger at the Max Planck Institute of Colloids and Interfaces in Golm (MPIKG), Germany. He obtained his degree in Chemistry at the University of Barcelona in 2004. The same year he joined the Stranski Laboratory at the Technical University in Berlin, where he obtained his PhD in Physical Chemistry in 2008. From 2008 to 2012 he was coordinating the project "Nanotox" at the Federal Institute for Materials Research and Testing in Berlin (BAM).

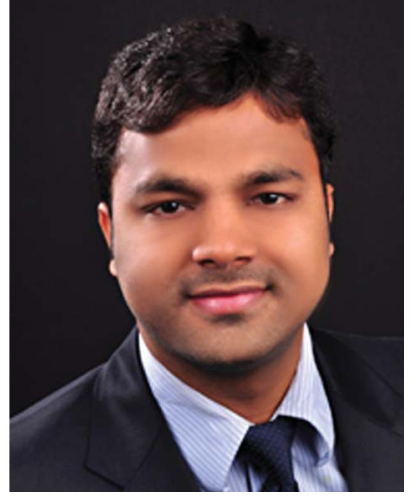

Kishore Natte studied MSc. Organic Chemistry in 2007 at the Kakatiya University, India. From 2007-2009 he worked as a Senior Chemist in GVK Biosciences Private Limited, Hyderabad, India. He moved to Germany in 2009 and completed his PhD on hybrid nanoparticles in December 2012 in the group of Professor Regine von Klitzing at the Technical University in Berlin in collaboration with BAM. In 2013, he joined the research group of Kishore Natte Professor Matthias Beller in Leibniz-Institute für Katalyse e.V. at Rostock University, for his postdoctoral research. His research interests are nanoparticles, carbonylations and transition metal catalysis. 
The conjunction of the above mentioned aspects led in the last years to an intensive activity in developing methods, mostly in vitro, in order to evaluate the potential impact of ENPs on biological systems and, at least, to distinguish between low and high toxicity nanomaterials. ${ }^{7-11}$

The planning of in vitro tests for nanotoxicological studies involves several aspects such as: sample preparation, selection of the appropriate cell type, definition of dose ranges corresponding to realistic exposition scenarios and selection of the appropriate methods for monitoring cell reactions. ${ }^{10}$ For some of the mentioned experimental parameters precise standard operation protocols (SOP) already exist or are being developed. The Organisation for Economic Co-operation and Development (OECD) concluded in 2012 after six years of study that: "the approaches for the testing and assessment of traditional chemicals are in general appropriate for assessing the safety of nanomaterials, but may have to be adapted to the specificities of nanomaterials". ${ }^{12}$ Nevertheless, in addition to SOPs, toxicologists also need reference materials in order to validate their methods and, consequently, be able to deliver reliable results. Unfortunately, in the last ten years, toxicologists often did not perceive ENPS characterisation as a crucial aspect when performing toxicological tests. This situation is gradually changing and the importance of a more exhaustive characterisation of ENPs previous to toxicological studies has been taken more seriously into consideration. ${ }^{13,14}$ Nevertheless, although many efforts are being done in order to provide RMs for toxicology, actual activities focus on the metrological traceability of single characteristics of ENPs like size and composition, but may ignore critical parameters like agglomeration and formation of protein corona in testing media. ${ }^{15}$

The aim of the present contribution is to point out the need and feasibility of an extended characterisation of ENPs in order to obtain well defined, multi-parametric, RMs for toxicology.

We present silica nanoparticles (SNPs) as a good starting point for a RM with an extended characterisation.

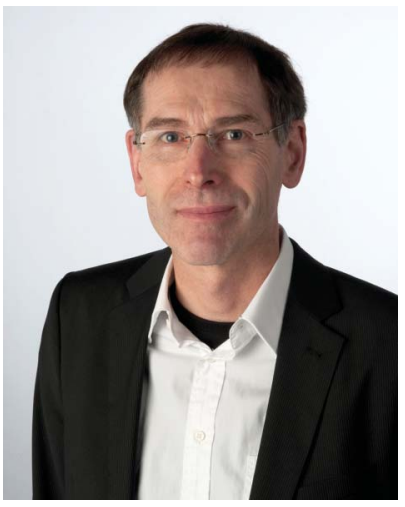

Werner Oesterle studied Materials Science and received a doctoral degree in physical metallurgy. He joined BAM in 1981 and became head of the working group "Electron Microscopy". He supervised numerous research projects focusing on the correlation between microstructure and material properties. Since 1998 he is working on tribologically induced nanostructured surface films, and since 2008 also on the characterWerner Österle ization of nano-objects using focused ion beam techniques and analytical transmission electron microscopy. During 30 years of research he has published more than 150 technical papers either as an author or co-author.
Furthermore, the perspective of future RM based on hybrid nanoparticles is discussed.

\subsection{Exposure of nanoparticles to humans and environment: released ENPs and wear nanoparticles}

For decades, industry has been producing different kinds of ENPs intentionally for a variety of products, which may potentially lead to the release of nanoparticles in the atmosphere in form of agglomerates and fibers. ${ }^{16}$ Also, the application of new ENPs in products that are used directly by consumers opened new routes of uptake by humans, for instance by inhalation, ingestion and dermal absorption. ${ }^{16}$

Besides the necessity to assess the potential risks associated to ENPs scientists should not forget that conventional technical materials are often covered with nanocrystalline surface films from which nanoparticles (NPs) can be emitted to the environment. $^{16}$ The latter scenario especially applies to nanostructured tribofilms which may develop on all kinds of tribological couples during dry friction or boundary lubrication. ${ }^{17}$ A particular critical case is total joint arthroplasty which may cause the release of particles into adjacent tissue. Although it seemed that the problem of aseptic loosening of hip implants caused by micrometre-sized polyethylene particles had been solved by replacing the polymer with ceramic parts, there is still concern about the observed release of a small amount of ceramic nanoparticles. ${ }^{18}$ Recent studies by Zhang et al. ${ }^{19}$ suggested that certain types of ceramic nanoparticles, i.e. zirconia and silicon nitride, can cause irritations of osteoblast-like and macrophagic cell lines. A second critical case might be the release of particles from friction brakes, the socalled brake dust. It has been proven many times by aerosol measurement techniques that numerous brake dust particles show diameters smaller than $100 \mathrm{~nm}$, as reviewed by Gasser et $a l .{ }^{20}$ Furthermore, to the best of our knowledge, this study is the only one considering "potential toxicological effects of human epithelial lung cells exposed to freshly generated brake wear particles". ${ }^{20}$ A possible drawback of both studies ${ }^{19,20}$ and also of most studies cited in the following, is that the agglomeration state of the particles was not checked prior to testing in cell culture media. This is not yet state of the art, but should be considered in the future by developing adequate testing procedures and appropriate reference materials.

\subsection{Outcome of in vitro biochemical assays-cellular uptake of nanoparticles}

Despite several contributions that have suggested a low correlation between the output of in vivo and in vitro tests, ${ }^{21}$ the latter still concentrate most of the researchers efforts when screening toxicity from new materials and studying the corresponding mechanisms. Nevertheless, traditional in vitro assays have been designed for testing soluble molecules. ${ }^{22}$

This may be one of the reasons explaining non-concluding or contradictory results on the toxicity of nanoparticles. Therefore, in order to develop more realistic toxicological assays for nanoparticles, more sophisticated, specific and validated in vitro tests have been suggested. ${ }^{21}$

Despite open questions and discrepancies, the large existent literature reported in the last 20 years has led to basic understanding of toxicity arising from nanoparticles: 
a

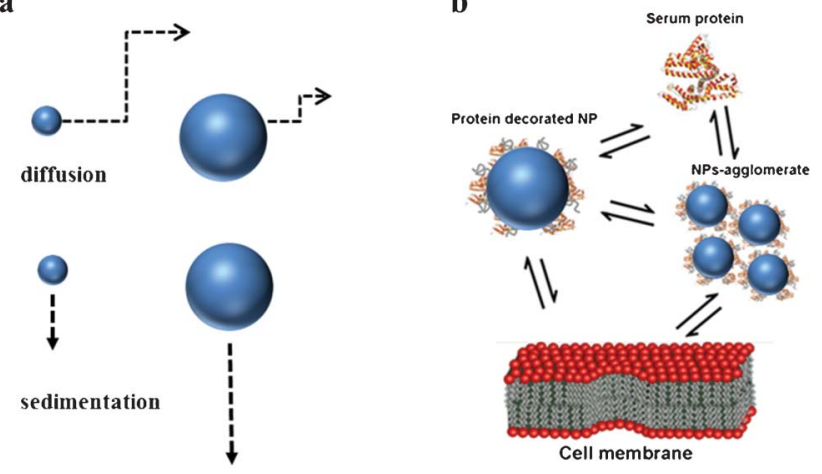

Fig. 1 processes involved in uptake mechanisms. (a) Diffusion and sedimentation. (b) Single or agglomerated nanoparticles coated with protein corona in biological media.

- The enormous specific surface area of nanoparticles plays a major role on their toxicity. ${ }^{23}$

- Serum proteins can reduce the toxicity of nanoparticles. ${ }^{24,25}$

- A proper characterisation of ENPs is a key point in nanotoxicology. ${ }^{13}$

- Metallic nanoparticles release radical oxidative species which damage cells. ${ }^{26}$

- Nanoparticles can be internalised by cells and especially by macrophages. $^{26}$

- Difference of sensitivity between cell types has to be carefully taken into account when assessing nanoparticles toxicity. ${ }^{27}$

- Protein corona on nanoparticles plays a major role in "what the cells see". ${ }^{28}$

Many studies have been performed in order to elucidate the effects of single properties on cell uptake pathways and intracellular distributions. The cellular uptake of nanoparticles depends on many factors like nanoparticle surface charge, size, shape, composition, agglomeration, sedimentation and diffusion as well as on the characteristics of the protein corona on the nanoparticles ${ }^{29,30}$ (Fig. 1). Here, internalization of nanoparticles by cells is driven by endocytosis, while larger objects are internalized by phagocytosis. ${ }^{31}$ Endocytosis transport is an active cell-mediated process by which cells plasma membrane continuously invaginates nanoparticles to form vesicles. ${ }^{32}$ Passive, non-endocytotic transport of nanoparticles has been rarely explored. ${ }^{32}$ Interestingly, in many cases nanoparticles protein corona is retained during nanoparticle uptake thus, protecting cells until proteins are degraded in the lysosomes. ${ }^{24}$

In the same way, a large number of in vitro and in vivo genotoxicity results have been reported. ${ }^{33}$ They led to the identification of primary genotoxic properties of nanoparticles, whereas recent in vivo studies further support a correlation between particle-induced lung inflammation and secondary genotoxicity effects. ${ }^{33}$

\section{Reference nanomaterials}

\subsection{Definition and different approaches}

As previously mentioned, a major requirement to develop methods for the risk assessment associated with ENPs is the use of RM. ${ }^{34,35}$ In 2011 the European Commission recommended the following definition of nanomaterials: "nanomaterial" means a natural, incidental or manufactured material containing particles, in an unbound state or as an aggregate or as an agglomerate and where, for $50 \%$ or more of the particles in the number size distribution, one or more external dimensions is in the size range $1 \mathrm{~nm}-100 \mathrm{~nm} \cdot{ }^{36}$ According to ISO Guide $30,{ }^{37} \mathrm{a}$ reference material is a "material, sufficiently homogeneous and stable with respect to one or more specified properties, which has been established to be fit for its intended use in a measurement process". Even more oriented to metrology is the ISO definition of a certified reference material: ${ }^{38}$ "material which is accompanied by a certificate, one or more of whose property values are certified by a procedure which establishes traceability to an accurate realisation of the unit in which the property values are expressed, and for which each certified value is accompanied by an uncertainty at a stated level of confidence". Thus, actual approximations to RMs for toxicology focus in the identification of those materials which may fulfil traceability requirements. ${ }^{39}$

Nevertheless, in addition to the mentioned traceability requirements, other considerations should be taken into account when thinking about a candidate as a RM for nanotoxicology:

(i) RM should be representative of existent materials. ${ }^{36}$ This lead to the formulation of priority lists, containing ENPs which are relevant in real environments or are expected to become relevant in the future. ${ }^{40}$

(ii) The chosen material should present some toxicity which can be evaluated with experimental methods.

(iii) A RM for nanotoxicology should be prepared in an adequate form to be used for toxicological studies. This means that parameters like initial concentrations, $\mathrm{pH}$, ionic strength, agglomeration state, etc. should be controlled and compatible with, for instance, in vitro studies. This may be one of the main challenges when thinking about a RM for nanotoxicology. In fact, most of existent nano-scaled RMs are "not ready to use" in toxicological tests since they are not conceived to be compatible with isotonic solution at physiological $\mathrm{pH}^{41}$

Due to the finding that the toxicity associated to nanoparticles depends on experimental conditions, an alternative approach to RMs would be the use of functionalised nanoparticles as proposed, for instance, by several authors from BAM and IUPAC. ${ }^{42,43}$ Thus, the surface modification of nanoparticles would produce more robust nano-RMs in terms of colloidal stability. ${ }^{43,44}$ This would allow performing toxicological experiments without being forced to control the agglomeration state of their dispersions prior and after in vitro testing. Examples of this second approach are presented in section 4 .

\subsection{National and international projects related to ENPs: increasing demand of reference materials and standardized methods}

In the last years, parallel to the industrial use of ENPs, an increasing concern about the potential impact on health and environment motivated several projects at national and international level (Table 1). However, only few projects focus specifically on the development of reference materials for toxicology. In 2008 BAM initiated the project NanoTox, with special focus on RMs. ${ }^{42}$ The same year, REFNANO project 
Table 1 list of several national and international projects related to risk assessment of ENPs. Acronyms can be found in section 5

\begin{tabular}{|c|c|c|c|}
\hline Project Name & Location & Starting year & Main goal \\
\hline Cell_Nano_Tox & EU, 5 countries & 2006 & risk of exposure to industrially manufactured NPs \\
\hline NanōTrust & ITA, Austria & 2007 & summarise the state of knowledge on nanorisk assessment \\
\hline Nanotox & BAM, Germany & 2008 & reference nanomaterials for toxicology \\
\hline NanoimpactNet & EU, 25 partners & 2008 & FP7 network for collaboration and communication \\
\hline NanoSustain & EU, 8 countries & 2010 & sustainable products and industrial applications \\
\hline REFNANO & IOM, UK & - & report on reference nanomaterials for toxicology \\
\hline NANOfutures & EU & 2010 & infrastructures and observatoires \\
\hline NanoValid & EU, 19 countries & 2011 & validation of methods for risk assessment of NPs \\
\hline MARINA & EU, several countries & 2011 & validation of Methods for risk assessment of NPs \\
\hline QNano & EU, 27 partner & 2011 & infrastructures and observatoires \\
\hline
\end{tabular}

located in UK, started with the same aim. ${ }^{45}$ The idea of NanoTox project was the development of a RM based on toxicologists demand of well-defined robust RMs based on silica (e.g. defined size, composition and dispersion in cell culture media) which are not yet available. ${ }^{25,44}$

Common point between all existent projects is the need of an interdisciplinary work between chemists, physicians, biologists and toxicologists in order to assess toxicological issues regarding nanoparticles with standardized RMs.

Some of the projects listed in Table 1 do not work directly on risk assessment of ENPs but adopt the function to maximise synergies between existing European projects (NanoSafety) or offer technical facilities (QNano). Recently starting European projects like NanoValid and Marina have some work packages focusing on the development of RMs for nanotoxicology, offering a good opportunity to provide RMs with certified values in more than only in particle size or only composition (Table 1).

\subsection{Available reference nanomaterials: mono-parametric and not ready to use}

The need of well characterised ENPs for toxicological issues even led to commercial products developed by private companies. Nevertheless, in this paper we will focus on RMs and certified RMs. Table 2 shows a selection of existent reference nanomaterials or those being currently in the state of development. Other lists presented in the literature only deal with RMs in terms of size. ${ }^{46}$

It can be concluded that actual approaches to RMs are mainly based on the metrological traceability of one of the following three properties: size, purity or in some specific surface area. In any case, actual approaches to RM can be defined as one-parametric. Nevertheless, the accurate determination of only one of these properties seems to be insufficient to assess the biological impact associated with nanoparticles. ${ }^{15}$ For instance, whether a measurand is related to a size effect on the nanometre scale it is extremely important to ensure that the cells are exposed to single nanoparticles within the CCM and not to agglomerates. ${ }^{25}$ These properties which are relevant while addressing toxicological studies are resumed in the following section.

\subsection{Nanoparticles characterization prior to toxicological studies: priority properties and measurand traceability}

A systematic study about which properties are priority for risk assessment of ENPs has been recently reported by Stefaniak et al., who considered 28 studies from the literature. ${ }^{40}$ Following properties were the most frequently suggested:

Table $\mathbf{2}$ List of existent and in progress mono-parametric reference nanomaterials

\begin{tabular}{|c|c|c|c|c|c|c|}
\hline \multirow[t]{2}{*}{ Silica } & 1 & $20 \mathrm{~nm}$ size & ERM-FD100 & CRM & IRMM & for sale \\
\hline & 2 & $40 \mathrm{~nm}$ size & ERM-FD304 & CRM & IRMM & for sale \\
\hline & 4 & $30 \mathrm{~nm}$ size & RM 8012 & $\mathrm{RM}$ & NIST & for sale \\
\hline & 5 & $60 \mathrm{~nm}$ size & RM 8013 & $\mathrm{RM}$ & NIST & for sale \\
\hline Polystyrene & 6 & $60 \mathrm{~nm}$ size & SRM 1964 & SRM & NIST & for sale \\
\hline SWCNTs "bucky paper" & 10 & elemental composition & RM 8282 & $\mathrm{RM}$ & NIST & production in progress \\
\hline SWCNT & 11 & 200,400 and $800 \mathrm{~nm}$ lenght & RM 8281 & $\mathrm{RM}$ & NIST & Fall 2012 \\
\hline \multirow[t]{3}{*}{ Silver } & 12 & $10 \mathrm{~nm}$ size & RM8016 & $\mathrm{RM}$ & NIST & in production \\
\hline & 13 & $35 \mathrm{~nm}, \mathrm{~d}_{90}$, volume-weighted & BAM-N001 & CRM & BAM & for sale \\
\hline & 14 & $75 \mathrm{~nm}$ size & RM8017 & $\mathrm{RM}$ & NIST & in production \\
\hline
\end{tabular}

${ }^{a}$ Only nanomaterials with nominal sizes below $100 \mathrm{~nm}$ are considered. ${ }^{b}$ Values shown here are approximate since nominal size depends on experimental technique. ${ }^{c} \mathrm{RM}=$ reference material; $\mathrm{CRM}=$ certified reference material; SRM = standard reference material certified by NIST.

${ }^{d}$ Until July 2012. This is a selection and not a fully list of ENPs. For more information please consult updated BAM reference materials database. ${ }^{47}$ 
Table 3 Physico-chemical (PC) properties of nanoparticles and corresponding experimental techniques. Acronyms are listed in section 6

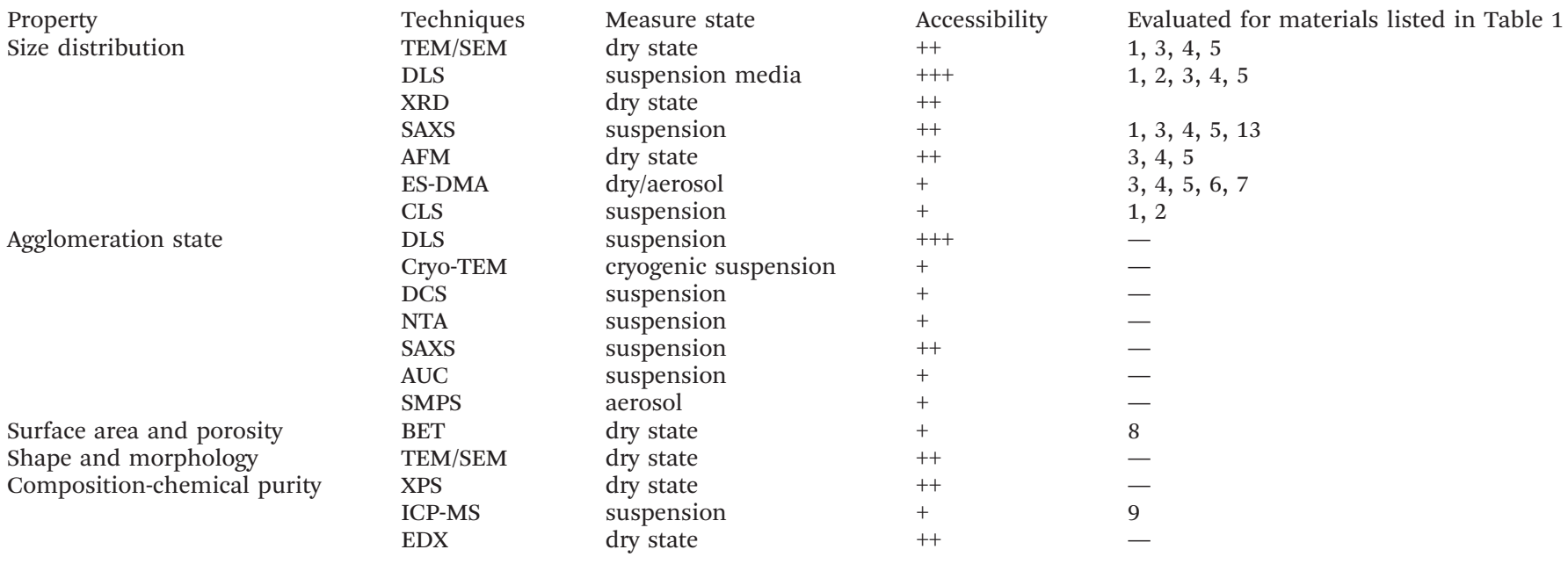

surface area (100\%), elemental composition (96\%), surface chemistry $(89 \%)$, particle size $(86 \%)$, particle size distribution (86\%), morphology-shape (86\%), surface charge (86\%), agglomeration state (71\%), and crystal structure (61\%).

Up to date, it has been shown that particle size is a traceable property for spherical particles like silica and gold (Table 2). The European association of National Metrology Institutes (EURAMET) demonstrated the feasibility to determine nanoparticle size with an uncertainty of less than $1 \mathrm{~nm}$. Traceability for other properties like composition and surface area are being evaluated for a series of different materials and, up to now, has only been proven for SWCNTs and $\mathrm{TiO}_{2}$, respectively Thus, particle size, surface area and composition can be considered as traceable properties which may be determined for a first multiparametric RM (green triangle in Fig. 2). Nevertheless, traceability for other properties still remains an open question, which must be answered for the development of new RMs.

Nevertheless, besides traceable properties which may produce certified RMs, other characteristics may be of vital importance when assessing toxicity associated with ENPs.

For instance, agglomeration in the suspension media has been recently shown to affect toxicity arising from silica, ${ }^{15,25}$ silver titanium dioxide ${ }^{48}$ and gold $^{49}$ nanoparticles. Unfortunately, the evaluation of the colloidal stability of NPs in serum-rich media can not be so easily assessed as in water due to the massive presence of proteins with concentrations typically exceeding the ones of NPS by three orders of

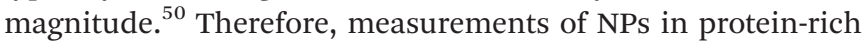
media often show broad size distributions which complicate the in situ measurement of aggregation size by methods like dynamic light scattering (DLS) or laser diffractometry (LD). For this reason, up to now, NPs characterisation in terms of agglomeration has been commonly reported in the absence of serum or only by using the supernatant phase of centrifuged nanoparticles-serum suspensions. ${ }^{51,52}$ Other methods to measure the distribution of NP-protein populations ex situ like ultracentrifugation (AUC) have been proposed. ${ }^{9,53}$ Also other techniques (see Table 3) like nanoparticle tracking analysis (NTA) have emerged in the last years and are being successively more standardised. ${ }^{54}$ On the other hand, the validity of DLS to detect some degree of agglomeration can still be accepted..$^{55,56}$

\subsection{Priority ENPs and their potentiality as multi-parametric RMs}

Stefaniak et al. summarised the five lists of nano-objects which were identified as an object of interest by NIST, REFNANO, OECD, NanoImpactNet and Nanovalid. ${ }^{40}$ Between 25 classes of nano-objects only four appeared in all lists: silver, gold, titanium dioxide and silica nanoparticles. In the following we briefly discuss the state-of-the-art of every of these four ENPs and focus on silica as a candidate for a multi-parametric RM in section 3.

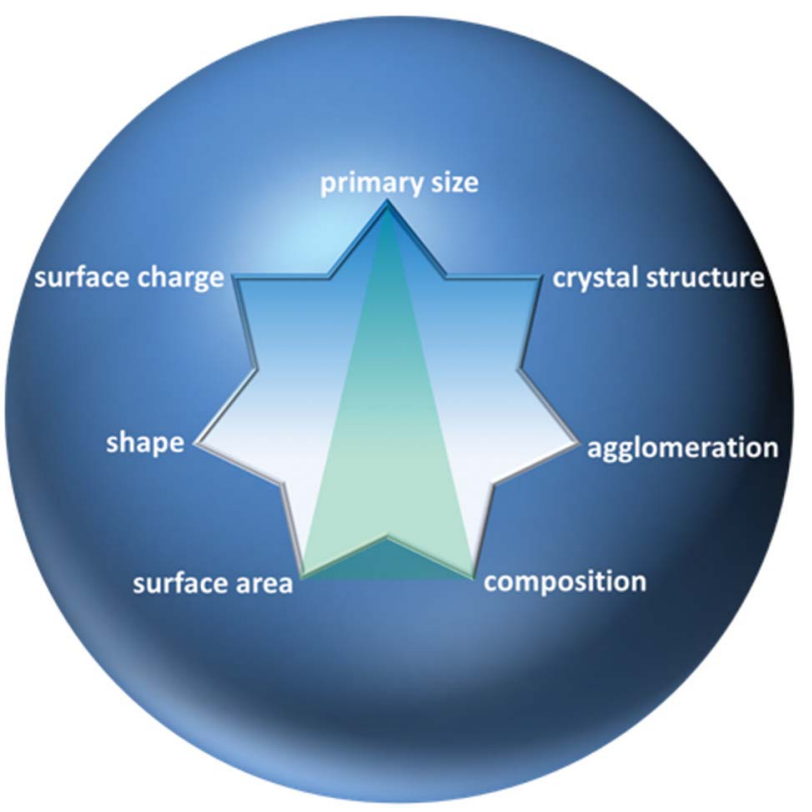

Fig. 2 Some properties of NPs suggested as priority for toxicological studies by various authors. ${ }^{40}$ Green triangle: possible traceable properties of a multiparametric reference material for nanotoxicology. 
- Silver nanoparticles (Ag-NPs). Antibacterial and antimicrobial activity associated to $\mathrm{Ag}-\mathrm{NPs}^{57,58}$ promoted their use or potential use in a large variety of biomedical commercial products like orthopaedic implants and clothes. ${ }^{59}$ Moreover, they present interesting optical properties for biomedical research. ${ }^{60}$

Nevertheless, adverse effects from Ag-NPs as reduction in glutathione levels, increase of ROS levels and lipid peroxidation have been already reported. Although, up to now, few publications focused on genotoxicity, it has been observed that Ag-NPs also induced DNA damage and apoptosis. ${ }^{61}$

Therefore, Ag-NPs will probably be one of the coming RMs. Here, advances in development of methods allowing controlled synthesis of spherical and monodisperse particles and certification of parameters like size and composition seem to be plausible. ${ }^{62}$

Nevertheless, present prototypes of $\mathrm{Ag}$-NPs present some drawbacks when thinking about a multi-parametric RMs. For instance, the report from Join Research Center (JRC) for the material NM-300 shows that this material presents different shapes of particles and a biomodal distribution of sizes. ${ }^{63}$ Other drawbacks may be the uncertainty about which toxicity arises from particles or from silver ions, ${ }^{64}$ the variability of surface functionalities and the lack of colloidal stability under certain conditions. ${ }^{65}$

- Gold nanoparticles (Au-NPs). Au-NPs are considered biocompatible and no acute cytotoxicity has been observed so far. ${ }^{66}$ On the other hand, similar to $\mathrm{Ag}-\mathrm{NPs}$, optical properties of $\mathrm{Au}-\mathrm{NPs}$ make them also very interesting for biomedical research. ${ }^{60}$ Traceability of gold nanoparticle in terms of size has been certified by NIST (see Table 2).

In the past 6 years, there had been a continuous increase of research activity in the biodistribution and toxicity of AuNPs. ${ }^{67}$ Some authors have proposed that, oppositely to silver, Au-NPs do not generate significant amounts of toxic ions. ${ }^{66}$ Nevertheless, negative effects to cytoskeletal components and a reduction in cell growth in human dermal fibroblasts have also been reported ${ }^{68}$ along with enhanced ROS levels in exposed samples. ${ }^{69}$ It has been also shown that $1.5 \mathrm{~nm} \mathrm{Au}-\mathrm{NPs}$ presents toxicity and accumulate in animal liver and spleen. Thus, colloidal gold may not be as bio-inert as assumed. ${ }^{67}$ For gold nanorods, the stabilizer cetyltrimethylammonium bromide (CTAB) also presents toxic effects. ${ }^{70}$

$\mathrm{Au}-\mathrm{NPs}$ are surrounded by a shell of stabilizing agent, typically citrate. As citrate-stabilized NPs are not stable for long times, more strongly binding ligands are often used. However, little is known about the amount of adsorbed molecules and the degree of change in respect to the original citrate. ${ }^{71}$ Although NIST reported the composition of gold nanoparticles, only insufficient information about the uncertainty of these measurements is available.

Colloidal stability of gold nanoparticles in biological media may be also object of further studies. Zhang et al. showed that $\mathrm{Au}-\mathrm{NPs}$ can induce the formation of protein-based aggregates at physiological $\mathrm{pH}^{72}$

- Titanium dioxide nanoparticles $\left(\mathrm{TiO}_{2}-\mathrm{NPs}\right)$. This material is being primarily used as a pigment but it can also be found in food, personal care and other commercial products. ${ }^{73}$

Although the Food and Drug Administration (FDA) allows since 1999 the use of nanoparticles in sunscreens, there has been a controversy regarding the safety of their use. In the case of $\mathrm{TiO}_{2}-$
NPs there are many studies proving the generation of ROS when they are exposed to UV light indicating a potential risk for health. ${ }^{74}$

The electronic structure and crystalline phases of titanium dioxide have been extensively investigated. ${ }^{75}$ Moreover, extensive efforts have been done on $\mathrm{TiO}_{2}-\mathrm{NPs}$ in the last years. As a result, the reference material called SRM 1898 with certified specific surface area for commercial P25 material has been recently presented (see Table 1 ). In addition to specific surface area, NIST and other sources also reported informative values about the crystallite sizes, phase fractions and chemical composition of P25. ${ }^{76,77}$ Thus, despite the actual uncertainty about whether these informative values could also be certified, this material may potentially become the first multi-parametric RM material based on titanium dioxide. Nevertheless, no extended information is available about other properties like size distribution. ${ }^{73}$ One main problem when thinking about traceability of $\mathrm{TiO}_{2}-\mathrm{NPs}$ is the fact that particles present significant anisotropy thus, making it difficult to determine their size. Another drawback may be that $\mathrm{TiO}_{2}-\mathrm{NPs}$ are typically coated with aluminium, silicon or polymers. ${ }^{73}$

- Amorphous silica nanoparticles (SNPs). Synthetic amorphous silica nanoparticles (SNPs) have been used since decades in many different commercial products: as a strengthening agent in silicone rubber, as a gelling agent in cosmetics, and as a viscosity modifier in paints, adhesives and sealants. ${ }^{78}$ SNPs are even considered to be safe and approved for use as a food or animal feed ingredient by FDA. ${ }^{79}$

Moreover, SNPs have more recently increasingly been used in diagnostic and biomedical research because of the facile production methods, their relative low cost and especially due to the fact that they are considered as non- or less-toxic. ${ }^{51}$ Nevertheless, several contributions proved toxicity associated with amorphous silica nanoparticles depending on several parameters like particle size and serum content of test media. ${ }^{25,52,80-85}$

However, more research is needed on nanosilica toxicity mechanisms, for instance how SNPs are absorbed from the gastrointestinal tract. ${ }^{86}$ Therefore, further studies with standard materials has been strongly proposed in order to enable comparison of experimental results for different forms of nanosilica. ${ }^{87}$

\section{Multi-parametric RMs: silica as a case study}

SNPs of different size can easily be synthesized by the well-known Stöber method ${ }^{88}$ or by the method described by Davis, if particles $<20 \mathrm{~nm}$ are desired. ${ }^{89}$ SNPs synthesized by these methods provide spherical shape and the surface of the SNP offers a wide variety of surface functionalization. Spherical shape of nanoobjects make them a good model and traceable material, e.g. for techniques assuming spherical shape like DLS (Fig. 3-c).

Unfortunately, existent certified materials based on silica are not suitable for nanotoxicology. First, they are only well characterized in terms of size (one-parametric RM) and, even more important, they are "not ready to use". For instance ERMFD100 and ERM-FD304 contain ions and solutions as stabilizing agents and high $\mathrm{pH}$ values which may potentially 


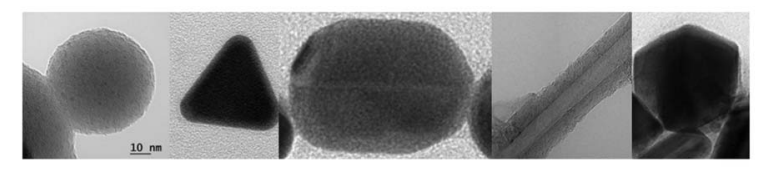

b

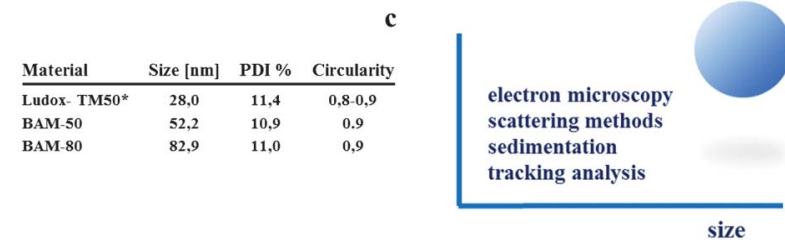

Fig. 3 (a) NPs with different geometries investigated within BAM project "NanoTox". From left to right: spherical silica, triangular silver, cylindrical gold, carbon nanotubes and icosahedral silver. (b) Nominal sizes of silica nanoparticles synthesized at the BAM as computed from TEM micrographs (results in supplementary section). All samples present high circularity. * From reference 44. (c) Comparable particle sizes for spherical nanoparticles like silica can be computed by at least four methods: electron microscopy, scattering methods like DLS and SAXS, tracking analysis techniques like NTA and sedimentation techniques like DCS. ${ }^{12,90}$ Low deviation between techniques can be attributed to particles monodispersity and high sphericity.

interfere with the outcome of, for instance, in vitro experiments. Nevertheless, such inconvenience does not necessarily contradict the potentiality of silica as a multi-parametric RM for nanotoxicology. In the following, we discuss one by one, the possibilities to overcome the difficulties with silica RMs.

\subsection{Traceable properties}

Materials which intrinsically possess certain characteristics as symmetry (sphericity), narrow size distributions after synthesis and good dispersivity are expected to fulfil metrological conditions easily. The properties presented in this section are potentially susceptible of being metrological traceable.

3.1.1 Shape and size. The successive development of synthetic methods has allowed obtaining nanoparticles of practically any geometry. Fig. 3-a shows some examples of nanoparticles with different shape investigated within BAM project "NanoTox". Nevertheless, those particles which present high symmetry, e.g. spheres, are better suited for analysis of their sizes, since many techniques assume this geometry (Fig. 3-c).

According to the definition by Wadell $^{5}$ a perfect spherical particle would have a sphericity of 1 and particles with any other shape have sphericity $<1$.

Here, some commercial silicas like Ludox-SM-30 and Ludox TM-50 present high sphericity and monodispersity, comparable to those materials prepared in the laboratory (see Fig. 3b). In fact, as previously mentioned, some materials based on commercial SNPs have been already certified for instrumental quality control (FD-100 (20 nm), FD-304 (40 nm), indicating a traceability of SNPs in terms of size by different methods like DLS, CLS, EM and SAXS. ${ }^{90}$

In addition, many efforts are being done in order to establish alternative techniques for size validation like NTA or SIOS. Bell et al. ${ }^{12}$ present an interesting study comparing emerging and established techniques to silica nanoparticles, evaluating their sizing precision and relative resolution. ${ }^{12}$
3.1.2 Chemical composition. The chemical purity of RMs, both nanoparticles and suspension media, must be assured if these materials are aimed for the toxicological studies. Here, chemical composition as reported from the manufacturer may be carefully considered. This is the case for carbon nanotubes where metals like Mn, Cd, or iron can substantially affect their toxicity. For this reason, different methods like e.g. thermal plasma $^{91}$ have been proposed in order to purify MWCNTs and SWCNTs. Another source of uncertainty while measuring the toxicity associated to ENPs may be the presence of functional groups on the surface of the nanoparticles which can significantly change their biological activity. ${ }^{92}$ For instance, Oslakovic et al. showed that carboxylated and aminated polystyrene nanoparticles induce opposite effects on the generation of thrombin in plasma. ${ }^{93}$

In the case of silica, the development of reference materials based on commercial materials may also generate some uncertainty. For instance Ludox TM50 (starting material for ERM-FD304) contains several impurities. ${ }^{94}$ Although the purification of commercial silicas is in principle possible, e.g. by dialysis. ${ }^{44,95}$ This is time consuming and tedious and does not assure the chemical purity of the nanoparticles themselves. Therefore, laboratory synthesis and purification of nanoparticles seems to be a better way in order to assure the chemical purity of materials. Silica nanoparticles with three different sizes were synthesized at the BAM and exhaustively purified. The purity of the prepared ENPs was evaluated by XPS. In these cases no traces of metal impurities were found. ${ }^{96}$ This implies that silica nanoparticles prepared by sol-gel methods may fulfil requirements for composition certification, at least "in house certification" as done in NIST for gold nanoparticles. The certification of the chemical composition of SNPs via interlaboratory comparison could also be the object of interest in current projects about nanoparticles validation as NanoValid and MARINA.

3.1.3 Surface area and porosity. Specific surface area represents an important parameter when assessing toxicity associated with ENPs. ${ }^{23}$ Several authors showed that surface area can be conveniently determined by BET. ${ }^{76,95}$ In the case of amorphous silica nanoparticles, due to high sphericity and low porosity (pores are typically in sub-nanometric range) the surface area of SNPs does not diverge significantly from theoretical values. ${ }^{95}$ This means that specific surface area can be accurately calculated from experimental particle sizes for non-porous and spherical silica nanoparticles (Fig. 4-a). Rabolli et al., showed that toxicity of SNPs on macrophages in serum-free media depends on their surface area. ${ }^{23}$ Moreover, Yu et al. ${ }^{83}$ showed that the toxicity of SNPs on mouse keratinocytes depends on particle size in a similar way as on specific surface area (Fig. 4-b).

\subsection{Required additional information}

Besides traceable properties which may lead to produce certified RMs, other characteristics may be of vital importance when assessing toxicity associated with ENPs. In the following we discuss some of them with focus on silica.

3.2.1 Agglomeration state-colloidal stability in relevant media. As previously mentioned, agglomeration state in the suspension media has been shown to affect toxicity arising 
a

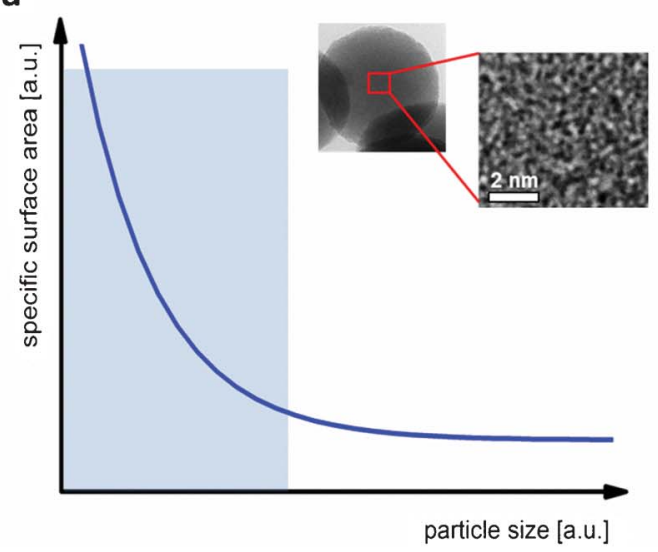

b

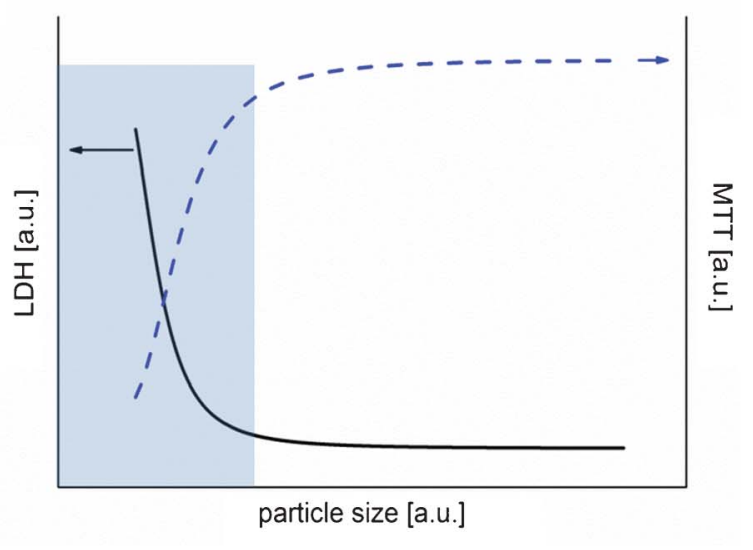

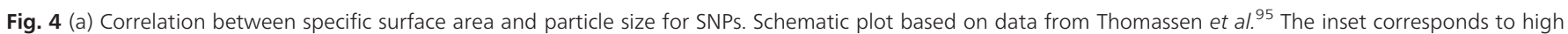

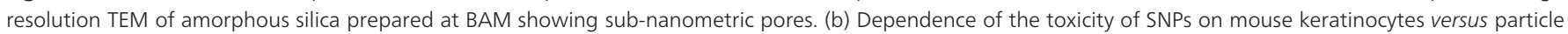
size. Schematic plot is based on data contained in the contribution from Yu et al. ${ }^{83}$ Transparent blue boxes represent the nanoscale regime (0-100 nm).

from different nanoparticles, ${ }^{15,25,48,49}$ as well as for silica. $^{25,44,97,98}$ Lin et al. $^{52}$ showed that SNPs with different sizes present similar agglomeration and toxicities. The results of Drescher et al. ${ }^{25}$ suggest that only single SNPs have been internalised by cells (Fig. 6-b).

However, elucidation of agglomeration behaviour of nanoparticles is not a trivial question depending on several factors like concentration, incubation conditions and composition of the media. ${ }^{96}$ In the case of silica, several authors reported colloidal stability of silica nanoparticles in pure water as well as in DMEM for at least several days due to electrostatic repulsion between charged surfaces. ${ }^{4495}$ Nevertheless, standard cell culture media used for in vitro studies are complex mixtures containing proteins, amino acids and vitamins. ${ }^{97}$ Thus, interparticle interactions may be significantly altered when proteins adsorb at the interface. ${ }^{96}$ In some cases protein adsorption can lead to de-agglomeration effect, as for $\mathrm{TiO}_{2}$ nanoparticles in serum/DMEM ${ }^{100}$ (Fig. 5-a-left). Oppositely, in water welldispersed silica tends to agglomerate in the presence of lysosome, ${ }^{101} \mathrm{BSA}^{44,96}$ or serum ${ }^{53}$ (Fig. 5-a-right). Interestingly, protein driven agglomeration of silica depends on nanoparticle/ protein ratio (Fig. 5-b). Thus, protein surface coverage plays a major role on the tendency of nanoparticles to agglomerate. Bharti et al. ${ }^{101}$ and Orts-Gil et al. ${ }^{96}$ hypothesized based on SAXS measurements that a bridging mechanism may be responsible for protein driven agglomeration observed for silica.

3.2.2 Characteristics of NP-medium interface. Several contributions reported zeta potential of nanoparticles in water or in buffered media. In the case of silica, zeta potential gradually decreases by addition of electrolytes. ${ }^{44}$ Nevertheless, this information may only be relevant when toxicological tests will be conducted in serum-free media. Thus, once NPs come into contact with biological environmental fluid they become rapidly surrounded by other molecules like vitamins and proteins. ${ }^{28}$ Therefore, NPs-medium interface and dispersivity in the suspension media may be the most critical characteristics which are altered going from stock solution to real suspension media. Fortunately, in the last years, first reports on the direct biological influence of proteins on the biological activity of nanoparticles have been published. For instance, Lesniak et al. ${ }^{102}$ showed that serum proteins critically affect cell adhesion and internalization of silica nanoparticles. Rezwan et al. reported the change in zeta potential for silica upon adsorption of bovine serum albumin and lysosome. ${ }^{103}$ Interestingly, in our previous work ${ }^{25}$ we showed that serum content substantially affects the colloidal stability and toxicity of $30 \mathrm{~nm}$ silica nanoparticles on eukaryotic cells in XTT assays (Fig. 6). On the other hand, Tenzer et al. ${ }^{104}$ showed that particle size substantially affects the composition of the serum corona. Dutta et al. ${ }^{105}$ showed that $10 \mathrm{~nm}$ amorphous silica coated with albumin induced anti-inflammatory responses in macrophages. Interestingly, a pre-coating of the nanoparticles with the nonionic surfactant Pluronic F127 inhibits the antiinflammatory properties of the nanoparticles, indicating once again that proteins modulate the uptake of amorphous SNPs.

Thus, the presence of proteins affects the biological activity related to silica nanoparticles. In many cases this information is not available.

- Surface coverage-corona thickness. Protein corona formation has been often described as a transition from a soft corona (rapid protein exchange rate) to a hard corona (slow exchange rate) which needs some time to equilibrate ${ }^{53}$ (see Fig. 7). Although silica nanoparticles have been characterised in serum media, some open question still remain concerning the protein corona characteristics. For instance, is not clear if serum proteins adsorb as mono- or multilayers on their surface. ${ }^{104}$ Nevertheless, this question will probably be solved soon since more efforts are being done. For instance, Gebauer et al. ${ }^{106}$ showed that circular dichroism allow to discriminate between the formation of protein mono- and multilayers on NP surfaces.

Furthermore, useful information about the protein corona can be obtained easily by means of zeta potential. ${ }^{96,103}$ In this way, it can be quantitatively scrutinised under which conditions the silica surface is significantly covered by the protein. Rezwan et $a .^{103}$ show that the amount of adsorbed BSA onto silica can be correlated by the evolution of the zeta potential 
$\mathbf{a}$

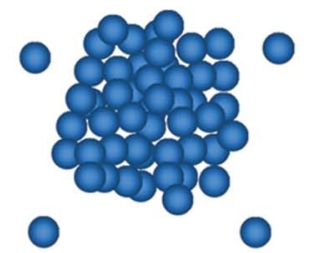
particles are well dispersed.

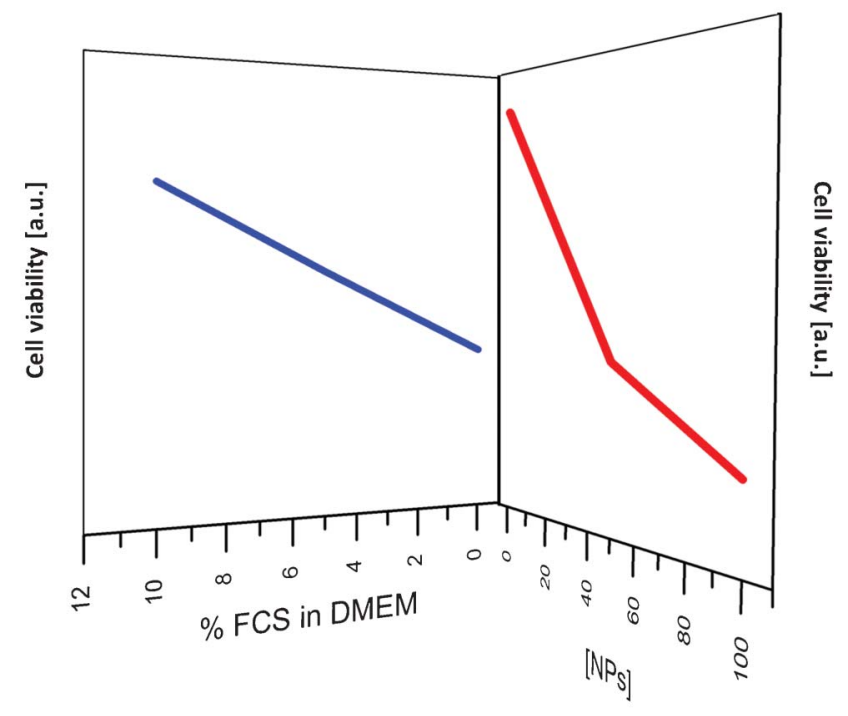

Fig. 6 Decrease in cell viability caused by silica nanoparticles on 3T3 cells depending on serum and nanoparticles concentration; schematic plot based on XTT assay data by Drescher et al. ${ }^{25}$

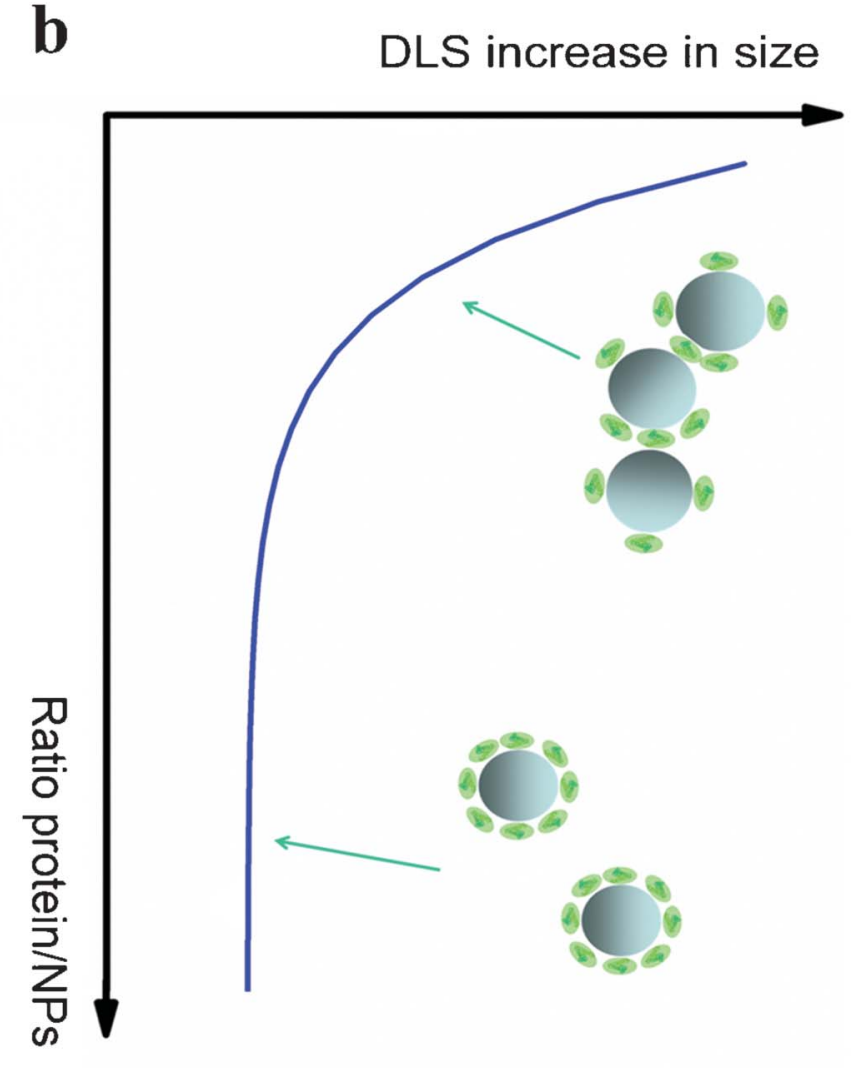

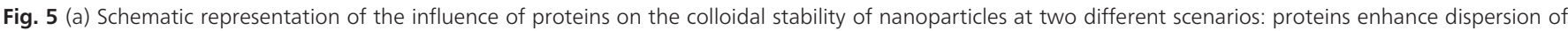
NPs (left) and proteins promote NPs agglomeration (right). (b) Colloidal stability of silica nanoparticles depending on serum/nanoparticle ratio (schematic curve

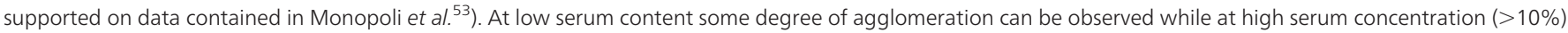

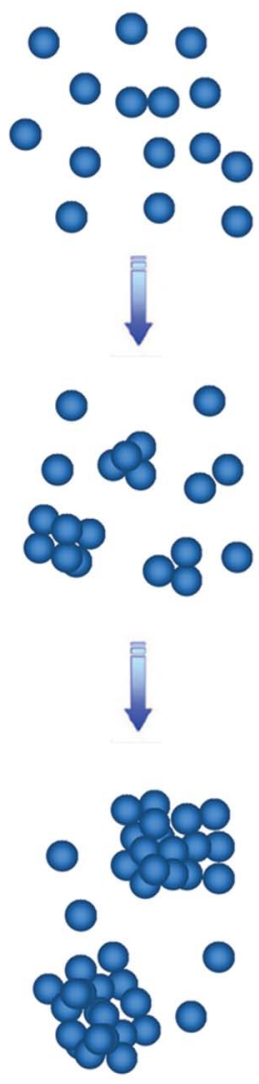

(ZP). On the other hand, Monopoli et al. ${ }^{53}$ presented a sophisticated and interesting approach to find out the thickness of serum corona on silica nanoparticles from DCS results by using a core-shell two-density model involving the particle material and adsorbed protein/biomolecule densities.

- Corona composition. Information about the composition of the nanoparticle corona in media containing serum is rarely available in the literature. Nevertheless, in words of Lynch, the protein corona is manly "what the cells see". ${ }^{28}$ Thus, more attention has been paid to this aspect in the last years. ${ }^{53,104}$ One possible reason for the lack of information may be the assumption that such information requires time consuming and expensive efforts. Nevertheless, different grades of complexity can be identified when speaking about protein corona determination: one or two page electrophoresis are widely available techniques which provide a first qualitative signature of the protein corona. For instance, Tenzer et al. ${ }^{104}$ showed by this technique that protein corona profiles, the so-called protein signature, already differ between 20 and $30 \mathrm{~nm}$ silica nanoparticles.

In a second level of complexity, liquid chromatography mass spectrometry (LC-MS) has also been used by Tenzer and 
a

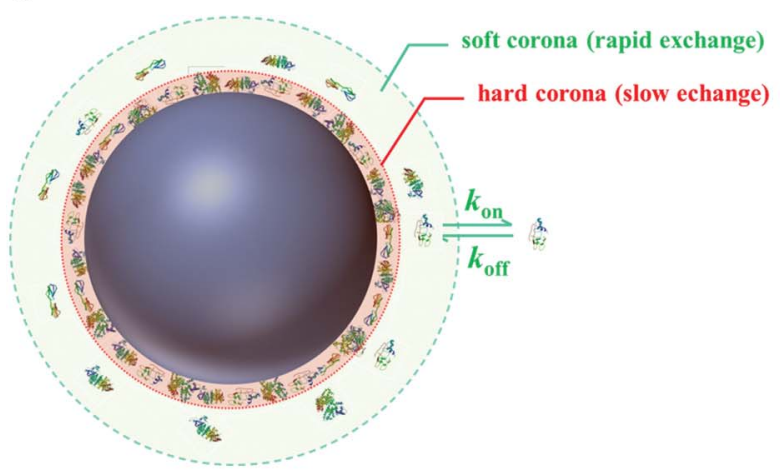

b

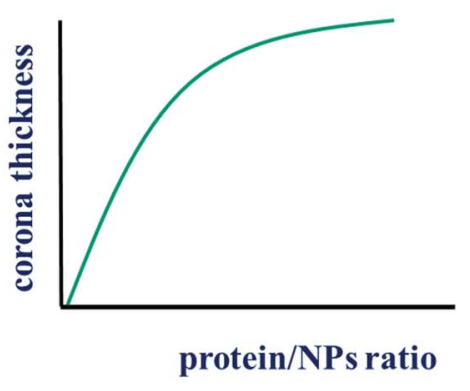

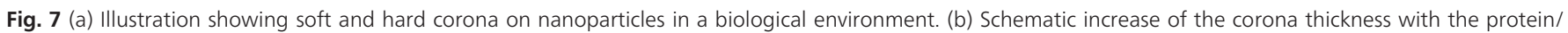
particle concentration ratio for silica based on data from Monopoli et al. ${ }^{53}$

colleagues in order to quantify the protein corona of silica nanoparticles with different sizes. The reproducibility of these results could be validated with a correlation coefficient of $\mathrm{R}^{2}>$ 0.98. The output of LC-MS analysis is that at least 125 different proteins present in serum, bind to the surface of silica.

In conclusion, specific analysis of corona composition in at least a first level of complexity might be widely available and useful when developing a RM for toxicology.

Moreover, recent simulation methods allow describing dynamics and time evolution of the corona formation. Such models can even be extended in order to model the interaction between an ENP and its target as shown by Dell'Orco et al. ${ }^{107}$

- Time evolution of protein corona. Already in the 1960's Leo Vroman reported that adsorption of blood serum proteins to an inorganic surface is time dependent. ${ }^{108}$ In a similar way, dynamic evolution of the protein corona onto nanoparticles has been more recently reported: fast or more abundant proteins interact first with nanoparticles surface and are later replaced by less mobile or abundant proteins with higher affinity. ${ }^{53}$ Casals et al. ${ }^{109}$ explored the formation and time evolution of protein corona formation onto Au-NPs. They show a transition from loosely attached to irreversible attached protein corona over time. The formation of a stable protein corona may take from few minutes, as in the case of silica, ${ }^{53}$ up to several hours as for Au-NPs. ${ }^{109}$

Despite time, also the particle size and ratio NPs/protein may influence protein corona formation. ${ }^{53,96,109}$

Fig. 8-a shows zeta potential values for Au-NPs in serumrich media depending on time and protein content. Fig. 8-b shows a numerical simulation of time evolution profiles of different human albumins onto nanoparticles, where the exchanging of fast proteins by those with higher affinities is illustrated.

\section{Future perspectives: hybrid nanoparticles as more robust RMs}

As previously exposed, the most common approach to RMs assumes that the material should be representative of existent relevant commercial materials. However, there is an increasing interest in the use of different types of functionalised or hybrid nanoparticles for a large variety of applications. ${ }^{111,112}$ Some examples of spherical nanoparticles with different architectures are shown in Fig. 9. Moreover, "bare" commercial nanoparticles often present drawbacks in terms of colloidal stability, which can drastically influence the outcome of toxicological tests. ${ }^{27,48}$ Therefore, the development of functionalised, colloidal stable RMs may be very interesting in order to improve comparability between different groups of scientists. $^{43}$ In fact, surface functionalization to gain colloidal stability is already common for silver and gold nanoparticles. ${ }^{65}$ In the case of silica, a convenient strategy to prepare silicaPEG hybrid nanoparticles without major synthetic efforts is the use of the one-step method reported by $\mathrm{Xu}$ et $a{ }^{113}{ }^{13} \mathrm{Diaz}$ et $a l .{ }^{97}$ reported that such silica-PEG nanoparticles present enhanced colloidal stability compared to pristine silica in serum-rich media. These results are in good agreement with our findings for the same nanoparticles in buffered BSA solutions. ${ }^{96}$ Therefore, the conception that hybrid nanoparticles are not representative of existent commercial NPs may also change in the next years.

\section{Conclusions}

In the last years, the need of a better characterisation of nanomaterials has emerged as a crucial aspect for the reliable assessment of the risk associated to ENP-handling and potential emission of NPs from technical materials. However, there is not a clear commitment about what minimum requirements are necessary to establish a reference material which can be used to validate and compare toxicology methods. Actual approaches to RMs for nanotoxicology are based on certification of one parameter (size or composition) and ignore other important characteristics like particle size distribution in real testing media and information about protein corona. Nevertheless, one-parametric RMs may probably be insufficient for the achievement of reliable and comparable toxicological studies. 
a

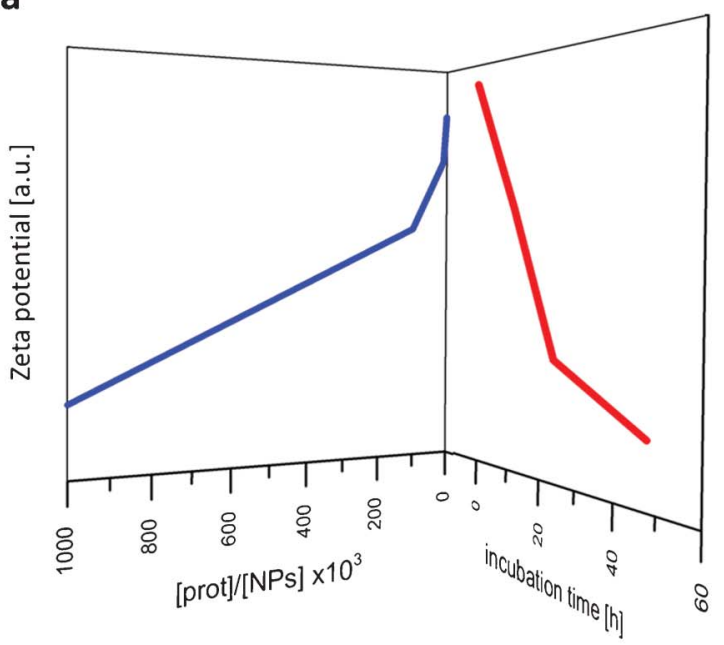

b

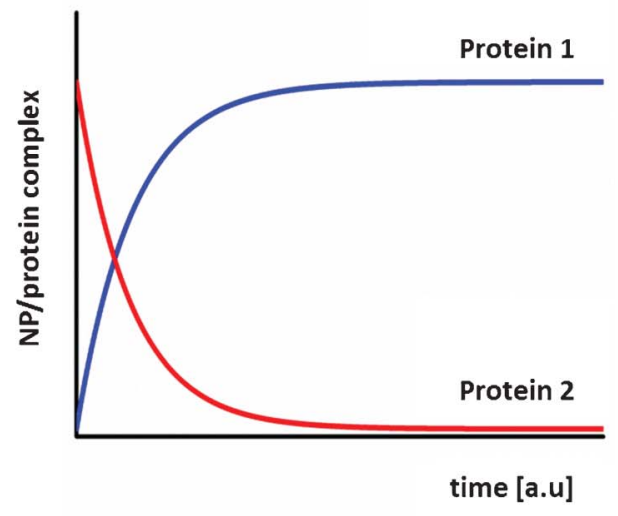

Fig. 8 (a) Decrease in zeta potential of gold nanoparticles depending on incubation time and serum content; schematic plot of the raw data by Casals et al. ${ }^{109}$ (b) Numerical simulation of time evolution profiles of two different human plasma proteins on nanoparticles; schematic plot from raw data by Dell'Orco et al. ${ }^{110}$
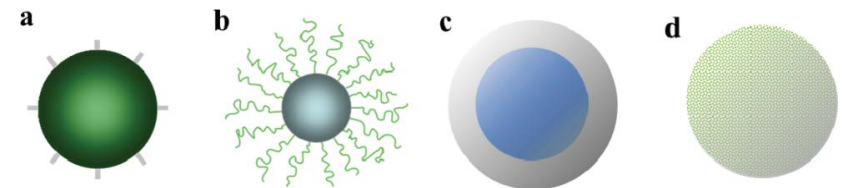

Fig. 9 Some examples of hybrid spherical nanoparticles: (a) NPs with short functional groups at surface; (b) NPs covered by polymeric chains; (c) inorganic core@shell NPs; (d) bulk hybrid nanoparticles.

In the present contribution the need of a new generation of multi-parametric reference materials is pointed out and discussed for priority ENPs.

Moreover, the importance of emerging organic-inorganic hybrid materials is also remarked.

\section{Supplementary material}

\subsection{Preparation of nanoparticles}

Silica particles BAM-50 and BAM-80 were prepared in ethanol following the well-known Stöber method. ${ }^{88}$ Silver and gold nanoparticles were prepared by following the methods described in ref. 115.

\subsection{TEM histograms}

TEM investigations were performed on a Jeol JEM 2200-FS operating at $200 \mathrm{kV}$. At high magnification, the in-column $\Omega$-filter was used to improve the contrast. Samples were prepared by immersion of grids of S-60-3 type (Cu coated with carbon film, Plano $\mathrm{GmbH})$ in a small volume $(0.5 \mathrm{~mL})$ of nanoparticle suspensions followed by solvent evaporation in a dust-protected atmosphere. Particle size distributions were obtained by analysing at least 200 NPs from TEM images using ImageJ software. ${ }^{116}$ Example of computed histogram for BAM50 is shown.

\section{Acronyms}

AFM
BET
CCM

Cryo-TEM

DLS

DSC

EDX

ENPS

ES-DMA

EU

ICP-MS

IRMM

ISO

ITA

MWCNTs

NIST

NPS

NTA

OECD

PC

RM

SAXS

SEM

SMPS

SNPs

SOPS

SWCNTS

TEM atomic force microscopy

gas adsorption according to ref. 114 cell culture media

cryogenic transmission electron microscopy

dynamic light scattering

disc sedimentation centrifugation

energy dispersive X-ray spectroscopy

engineered nanoparticles

Electrospray differential mobility analysis collaborative European project

inductive coupled plasma mass spectrometry

Institute for Reference Materials and Measurements

International Organization for

Standardization

Institute of Technology Assestment

multi-wall carbon nanotubes

National Institute of Standards and Technology

nanoparticles

nanoparticle tracking analysis

Organisation for Economic Co-operation and Development

physico-chemical

reference material

small angle X-ray scattering

scanning electron microscopy

scanning mobility particle sizer

amorphous silica nanoparticles

standard operation procedures

single wall carbon nanotubes

transmission electron microscopy 
AUC

XAS

XPS

XRD

analytical ultra centrifugation

X-ray absorption spectroscopy

X-ray photoelectron spectroscopy

$\mathrm{X}$-ray diffraction

\section{Acknowledgements}

Most of results and conclusions included in this paper are the outcome of the project NanoTox, supported by the Federal Institute for Materials Research and Testing (BAM) within the framework of its 'Innovationsoffensive' from 2008 to 2011. Furthermore, a small part of the research leading to these results has received funding from the European Union Seventh Framework Programme (FP7/2007-2013) under grant agreement $\mathrm{n}^{\circ} 263147$ (NanoValid - Development of reference methods for hazard identification, risk assessment and LCA of engineered nanomaterials. G.O.-G. acknowledges the group of Professor Janina Kneipp at BAM and Humboldt University in Berlin for preparation of gold and silver nanoparticles. A. Meyer-Plath is acknowledged for kindly providing carbon nanotubes samples.

\section{References}

1 S. Iijima, Nature, 1991, 354, 56-58.

2 C. Journet, W. K. Maser, P. Bernier, A. Loiseau, M. L. de la Chapelle, S. Lefrant, P. Deniard, R. Lee and J. E. Fischer, Nature, 1997, 388, 756-758.

3 Y. Lee, J. Lee, C. J. Bae, J. G. Park, H. J. Noh, J. H. Park and T. Hyeon, Adv. Funct. Mater., 2005, 15, 503-509.

4 J.-S. Hu, L.-L. Ren, Y.-G. Guo, H.-P. Liang, A.-M. Cao, L.J. Wan and C.-L. Bai, Angew. Chem., 2005, 117, 1295-1299.

5 W. Hakon, J. Geol., 1935, 43, 250-280.

6 G. A. C. o. t. E. (SRU), 2011.

7 T. Xia, M. Kovochich, J. Brant, M. Hotze, J. Sempf, T. Oberley, C. Sioutas, J. I. Yeh, M. R. Wiesner and A. E. Nel, Nano Lett., 2006, 6, 1794-1807.

8 A. M. G. Oberdoerster, K. Donaldson, V. Castranova, J. Fitzpatrick, K. Ausman, J. Carter, B. Karn, W. Kreyling, D. Lai, S. Olin, N. Monteiro-Riviere, D. Warheit and H. Yang, Particle and Fibre Toxicology, 2005, 2(8), 1-35.

9 R. Landsiedel, L. Ma-Hock, A. Kroll, D. Hahn, J. Schnekenburger, K. Wiench and W. Wohlleben, Adv. Mater., 2010, 22, 2601-2627.

10 G. Oberdörster, A. Maynard, K. Donaldson, V. Castranova, J. Fitzpatrick, K. Ausman, J. Carter, B. Karn, W. Kreyling, D. Lai, S. Olin, N. Monteiro-Riviere, D. Warheit and H. Yang, Part. Fibre Toxicol., 2005, 2, 8.

11 G. Oberdörster, V. Stone and K. Donaldson, Nanotoxicology, 2007, 1(1), 2-25.

12 N. C. Bell, C. Minelli, J. Tompkins, M. M. Stevens and A. G. Shard, Langmuir, 2012, 28, 10860-10872.

13 D. B. Wahrheit, Toxicol. Sci., 2008, 101, 183-185.

14 P. Rivera Gil, G. Oberdorster, A. Elder and V. P. W. J. Puntes, ACS Nano, 2010, 4, 5527-5531.

15 C. S.-E. B. Diaz, M. Arruebo, J. Faro, E. de Miguel, S. Magadan, C. Yague, R. Fernandez-Pacheco, R. Ibarra,
J. Santamarıa and A. Gonzalez-Fernandez, Small, 2008, 4, 2025-2034.

16 P. Borm, D. Robbins, S. Haubold, T. Kuhlbusch, H. Fissan, K. Donaldson, R. Schins, V. Stone, W. Kreyling, J. Lademann, J. Krutmann, D. Warheit and E. Oberdorster, Part. Fibre Toxicol., 2006, 3, 11.

17 S. Jacobson and S. Hogmark, Recent Developments in Wear Prevention, Friction and Lubrication, Research Signpost, India, 2010.

18 J. Fisher, Faraday Discuss., 2012, 156, 59-68.

19 Y.F. Zhang, Y. F. Zheng and L. Qin, Nanomed.: Nanotechnol., Biol. Med., 2011, 7, 975-982.

20 M. Gasser, M. Riediker, L. Mueller, A. Perrenoud, F. Blank, P. Gehr and B. Rothen-Rutishauser, Part. Fibre Toxicol., 2009, 6, 30.

21 C. M. Sayes, K. L. Reed and D. B. Warheit, Toxicol. Sci., 2007, 97, 163-180.

22 D. Lison and F. Huaux, Nat. Nanotechnol., 2011, 6, 332-333.

23 V. Rabolli, L. C. J. Thomassen, F. Uwambayinema, J. A. Martens and D. Lison, Toxicol. Lett., 2011, 206, 197-203.

24 F. Wang, L. Yu, A. Salvati and K. A. Dawson, Nanomedicine: Nanotechnology, Biology and Medicine.

25 D. Drescher, G. Orts-Gil, G. Laube, K. Natte, R. W. Veh, W. Österle and J. Kneipp, Anal. Bioanal. Chem., 2011, 400(5), 1367-1373.

26 M. Horie, H. Kato, K. Fujita, S. Endoh and H. Iwahashi, Chem. Res. Toxicol., 2011, 25(3), 605-619.

27 C. Fede, F. Selvestrel, C. Compagnin, M. Mognato, F. Mancin, E. Reddi and L. Celotti, Anal. Bioanal. Chem., 2012, 404, 1789-1802.

28 A. S. a. K. A. D. Iseult lynch, Nat. Nanotechnol., 2009, 4, 546-547.

29 B. D. Chithrani, A. A. Ghazani and W. C. W. Chan, Nano Lett., 2006, 6, 662-668.

30 E. C. Cho, Q. Zhang and Y. Xia, Nat. Nanotechnol., 2011, 6, 385-391.

31 T.-G. Iversen, T. Skotland and K. Sandvig, Nano Today, 2011, 6, 176-185.

32 S. K. Banerji and M. A. Hayes, Langmuir, 2007, 23, 3305-3313.

33 R. Schins, Inhalation Toxicol., 2002, 14, 57-78.

34 R. J. Aitken, S. M. Hankin, C. Lang Tran, K. Donaldson, V. Stone, P. Cumpson, J. Johnstone, Q. Chaudhry, S. Cash and J. Garrod, Nanotoxicology, 2008, 2, 71-78.

35 R. Owen and R. Handy, Environmental Science \& Technology, 2007, 41, 5582-5588.

36 Official Journal of the European Union, L, 2011, vol. 275/38.

37 International Organization for Standardization ISO Guide, 1992, vol. 30 .

38 ISO/IEC Guide, 2007, vol. 99.

39 V. Stone, B. Nowack, A. Baun, N. van den Brink, F. von der Kammer, M. Dusinska, R. Handy, S. Hankin, M. Hassellöv, E. Joner and T. F. Fernandes, Sci. Total Environ., 2010, 408, 1745-1754.

40 A. B. Stefaniak, V. A. Hackley, G. Roebben, K. Ehara, S. Hankin, M. T. Postek, I. Lynch, W.-E. Fu, T. P. J. Linsinger and A. F. Thünemann, Nanotoxicology, 1-13.

41 C. Schulze, A. Kroll, C.-M. Lehr, U. F. Schäfer, K. Becker, J. r. Schnekenburger, C. Schulze Isfort, R. Landsiedel and W. Wohlleben, Nanotoxicology, 2008, 2, 51-61. 
42 http://www.nano.bam.de/en/projekte/nanotox_refmat.htm.

43 L. Dean, Chemistry International, 2012, 34, 6-9.

44 G. Orts-Gil, K. Natte, D. Drescher, H. Bresch, A. Mantion, J. Kneipp and W. Österle, J. Nanopart. Res., 2011, 13, 1593-1604.

45 R. J. Aitken, S. M. Hankin, C. L. Tran, K. Donaldson, V. Stone, P. Cumpson, J. Johnstone, Q. Chaudhry and S. Cash, Nanotoxicology, 2008, 2, 71-78.

46 T. P. J. Linsinger, G. Roebben, C. Solans and R. Ramsch, TrAC, Trends Anal. Chem., 2011, 30, 18-27.

47 http://www.nano-refmat.bam.de/en/.

48 A. Lankoff, W. J. Sandberg, A. Wegierek-Ciuk, H. Lisowska, M. Refsnes, B. e. Sartowska, P. E. Schwarze, S. MeczynskaWielgosz, M. Wojewodzka and M. Kruszewski, Toxicol. Lett., 2012, 208, 197-213.

49 A. Albanese, P. S. Tang and W. C. W. Chan, Annu. Rev. Biomed. Eng., 2012, 14, 1-16.

50 N. Hondow, R. Brydson, P. Wang, M. Holton, M. Brown, P. Rees, H. Summers and A. Brown, J. Nanopart. Res., 2012, 14, 1-15.

51 T. Brunner, P. Wick, P. Manser, P. Spohn, R. Grass, L. Limbach, A. Bruinink and W. S. tark, Environ. Sci. Technol., 2006, 40, 4374-4381.

52 W. Lin, Y. Huang, X. Zhou and Y. Ma, Toxicol. Appl. Pharmacol., 2006, 217, 252-259.

53 D. W. M. Monopoli, A. Campbell, G. Elia, I. Lynch, F. Baldelli Bombelli and K. Dawson, J. Am. Chem. Soc., 2011, 133, 2525-2534.

54 ASTM E2834-12 Standard Guide for Measurement of Particle Size Distribution of Nanomaterials in Suspension by Nanoparticle Tracking Analysis (NTA), , DOI: $10.1520 / \mathrm{E} 2834-12$.

55 R. C. Murdock, L. Braydich-Stolle, A. M. Schrand, J. J. Schlager and S. M. Hussain, Toxicol. Sci., 2008, 101(2), 239-253.

56 H. Kato, M. Suzuki, K. Fujita, M. Horie, S. Endoh, Y. Yoshida, H. Iwahashi, K. Takahashi, A. Nakamura and S. Kinugasa, Toxicol. in Vitro, 2009, 23, 927-934.

57 J. S. Kim, E. Kuk, K. N. Yu, J.-H. Kim, S. J. Park, H. J. Lee, S. H. Kim, Y. K. Park, Y. H. Park, C.-Y. Hwang, Y.-K. Kim, Y.S. Lee, D. H. Jeong and M.-H. Cho, Nanomed.: Nanotechnol., Biol. Med., 2007, 3, 95-101.

58 C. Baker, A. Pradhan, L. Pakstis, J. Pochan Darrin and S. I. Shah, J. Nanosci. Nanotechnol., 2005, 5, 244-249.

59 V. K. Sharma, R. A. Yngard and Y. Lin, Adv. Colloid Interface Sci., 2009, 145, 83-96.

60 J. Kneipp, H. Kneipp, A. Rajadurai, R. W. Redmond and K. Kneipp, J. Raman Spectrosc., 2009, 40, 1-5.

61 R. de Lima, A. B. Seabra and N. Durán, J. Appl. Toxicol., 2012, 32, 867-879.

62 D. Steinigeweg and S. Schlucker, Chem. Commun., 2012, 48, 8682-8684.

63 C. Klein, S. Comero, G. Locoro, B. M. Gawlik, T. Linsinger, B. Stahlmecke, J. Romazanov, T. A. J. Kuhlbusch, E. Van Doren De Temmerman, J. Mast, P. Wick, H. F. Krug, S. Friedrichs, G. Maier, J. Werner, K. Hund-Rinke and W. Kördel, JRC 60709, EUR 24693 EN, 2011, p. 86.

64 C. Beer, R. Foldbjerg, Y. Hayashi, D. S. Sutherland and H. Autrup, Toxicol. Lett., 2012, 208, 286-292.
65 S. Kittler, C. Greulich, J. S. Gebauer, J. Diendorf, L. Treuel, L. Ruiz, J. M. Gonzalez-Calbet, M. Vallet-Regi, R. Zellner, l. M. Kö and M. Epple, J. Mater. Chem., 2010, 20, 512-518.

66 R. A. Sperling, P. Rivera Gil, F. Zhang, M. Zanella and W. J. Parak, Chem. Soc. Rev., 2008, 37, 1896-1908.

67 N. Khlebtsov and L. Dykman, Chem. Soc. Rev., 2011, 40, 1647-1671.

68 Y. Pan, S. Neuss, A. Leifert, M. Fischler, F. Wen, U. Simon, G. Schmid, W. Brandau and W. Jahnen-Dechent, Small, 2007, 3, 1941-1949.

69 Y. Pan, A. Leifert, D. Ruau, S. Neuss, J. Bornemann, G. Schmid, W. Brandau, U. Simon and W. JahnenDechent, Small, 2009, 5, 2067-2076.

70 K. Yu, S.-S. Chang, C.-L. Lee and C. R. C. Wang, J. Phys. Chem. B, 1997, 101, 6661-6664.

71 A. Rostek, D. Mahl and M. Epple, J. Nanopart. Res., 2011, 13, 4809-4814.

72 D. Zhang, O. Neumann, H. Wang, V. M. Yuwono, A. Barhoumi, M. Perham, J. D. Hartgerink, P. WittungStafshede and N. J. Halas, Nano Lett., 2009, 9, 666-671.

73 A. Weir, P. Westerhoff, L. Fabricius, K. Hristovski and N. von Goetz, Environ. Sci. Technol., 2012, 46, 2242-2250.

74 M. D. Newman, M. Stotland and J. I. Ellis, J. Am. Acad. Dermatol., 2009, 61, 685-692.

75 U. Diebold, Surf. Sci. Rep., 2003, 48, 53-229.

76 K. Suttiponparnit, J. Jiang, M. Sahu, S. Suvachittanont, T. Charinpanitkul and P. Biswas, Nanoscale Res Lett, 2011, 6, 27.

77 T. C. Long, N. Saleh, R. D. Tilton, G. V. Lowry and B. Veronesi, Environ. Sci. Technol., 2006, 40, 4346-4352.

78 DECHEMA/VCI working group. 10 Years of Research: Risk Assessment, Human and Environmental Toxicology of Nanomaterials, 2011, ISBN: 978-3-89746-129-1.

79 J.-S. Chang, K. L. B. Chang, D.-F. Hwang and Z.-L. Kong, Environ. Sci. Technol., 2007, 41, 2064-2068.

80 W. A. M. Park, A. Salvati, A. Lesniak, A. Elsaesser, C. Barnes, G. McKerr, C. Howard, I. Lynch, K. Dawson, A. Piersma and W. de Jong, Toxicol. Appl. Pharmacol., 2009, 240, 108-116.

81 C. Fruijtier-Pölloth, Toxicology, 2012, 294, 61-79.

82 Y. Li, L. Sun, M. Jin, Z. Du, X. Liu, C. Guo, Y. Li, P. Huang and Z. Sun, Toxicol. in Vitro, 2011, 25, 1343-1352.

83 K. O. Yu, C. M. Grabinski, A. M. Schrand, R. C. Murdock, W. Wang, B. Gu, J. J. Schlager and S. M. Hussain, J. Nanopart. Res., 2009, 11, 15-24.

84 H. Nabeshi, T. Yoshikawa, K. Matsuyama, Y. Nakazato, S. Tochigi, S. Kondoh, T. Hirai, T. Akase, K. Nagano, Y. Abe, Y. Yoshioka, H. Kamada, N. Itoh, S.-i. Tsunoda and Y. Tsutsumi, Part. Fibre Toxicol., 2011, 8, 1.

85 D. Napierska, L. C. J. Thomassen, V. Rabolli, D. Lison, L. Gonzalez, M. Kirsch-Volders, J. A. Martens and P. H. Hoet, Small, 2009, 5, 846-853.

86 S. Dekkers, H. Bouwmeester, P. M. J. Bos, R. J. B. Peters, A. G. Rietveld and A. G. Oomen, Nanotoxicology, 1-11.

87 D. Napierska, L. Thomassen, D. Lison, J. Martens and P. Hoet, Part. Fibre Toxicol., 2010, 7, 39.

88 W. F. A. Stöber and E. Bohn, J. Colloid Interface Sci., 1968, 26, 62.

89 T. M. Davis, M. A. Snyder, J. E. Krohn and M. Tsapatsis, Chem. Mater, 2006, 18, 5814-5816. 
90 A. Braun, V. Kestens, K. Franks, G. Roebben, A. Lamberty and T. J. Linsinger, J. Nanopart. Res., 2012, 14, 1-12.

91 A. Meyer-Plath, G. Orts-Gil, S. Petrov, F. Oleszak, H.E. Maneck, I. Dörfel, O. Haase, S. Richter and R. Mach, Carbon, 2012, 50, 3934-3942.

92 C. Freese, M. I. Gibson, H.-A. Klok, R. E. Unger and C. J. Kirkpatrick, Biomacromolecules, 2012, 13, 1533-1543.

93 C. Oslakovic, T. Cedervall, S. Linse and B. Dahlbäck, Nanomed.: Nanotechnol., Biol. Med., 2012, 8, 981-986.

94 K. Franks, A. Braun, J. Charoud-Got, O. Couteau, V. Kestens, A. Lamberty, T. P. J. Linsinger and G. Roebben, Institute for Reference Materials and Measurements (IR), 2012.

95 L. C. J. Thomassen, A. Aerts, V. Rabolli, D. Lison, L. Gonzalez, M. Kirsch-Volders, D. Napierska, P. H. Hoet, C. E. A. Kirschhock and J. A. Martens, Langmuir, 2010, 26(1), 328-335.

96 G. Orts-Gil, K. Natte, R. Thiermann, M. Girod, S. Rades, H. Kalbe, A. F. Thünemann, M. Maskos and W. Österle, Colloids Surf., B, 2013, 108, 110-119.

97 B. Díaz, C. Sánchez-Espinel, M. Arruebo, J. Faro, E. de Miguel, S. Magadán, C. Yagüe, R. Fernández-Pacheco, M. R. Ibarra, J. Santamaría and Á. González-Fernández, Small, 2008, 4, 2025-2034.

98 X. Xing, X. He, J. Peng, K. Wang and W. Tan, J. Nanosci. Nanotechnol., 2005, 5, 1688-1693.

99 C. Graf, Q. Gao, I. Schütz, C. Noufele, W. Ruan, U. Posselt, E. Korotianskiy, D. Nordmeyer, F. Rancan, S. Hadam, A. Vogt, J. Lademann, V. Haucke and E. Rühl, Langmuir, 2012.

100 Z. Magdolenova, D. Bilanicova, G. Pojana, L. M. Fjellsbo, A. Hudecova, K. Hasplova, A. Marcomini and M. Dusinska, J. Environ. Monit., 2012, 14, 455-464.

101 B. Bharti, J. Meissner and G. H. Findenegg, Langmuir, 2011, 27, 9823-9833.
102 A. Lesniak, F. Fenaroli, M. P. Monopoli, C. Äberg, K. A. Dawson and A. Salvati, ACS Nano, 2012, 6, 5845-5857.

103 K. Rezwan, A. R. Studart, J. Vörös and L. J. Gauckler, J. Phys. Chem. B, 2005, 109, 14469-14474.

104 S. Tenzer, D. Docter, S. Rosfa, A. Wlodarski, J. r. Kuharev, A. Rekik, S. K. Knauer, C. Bantz, T. Nawroth, C. Bier, J. Sirirattanapan, W. Mann, L. Treuel, R. Zellner, M. Maskos, H. r. Schild and R. H. Stauber, ACS Nano, 2011, 5, 7155-7167.

105 D. Dutta, S. K. Sundaram, J. G. Teeguarden, B. J. Riley, L. S. Fifield, J. M. Jacobs, S. R. Addleman, G. A. Kaysen, B. M. Moudgil and T. J. Weber, Toxicol. Sci., 2007, 100, 303-315.

106 J. S. Gebauer, M. Malissek, S. Simon, S. K. Knauer, M. Maskos, R. H. Stauber, W. Peukert and L. Treuel, Langmuir, 2012, 28(25), 9673-9679.

107 D. Dell'Orco, M. Lundqvist, T. Cedervall and S. Linse, Nanomed.: Nanotechnol., Biol. Med., 2012, 8, 1271-1281.

108 L. Vroman, Nature, 1962, 196, 476-477.

109 E. Casals, T. Pfaller, A. Duschl, G. J. Oostingh and V. Puntes, ACS Nano, 2010, 4(7), 3623-3632.

110 D. Dell'Orco, M. Lundqvist, C. Oslakovic, T. Cedervall and S. Linse, PLoS One, 2010, 5, e10949.

111 G. A. Sotiriou, A. M. Hirt, P.-Y. Lozach, A. Teleki, F. Krumeich and S. E. Pratsinis, Chem. Mater., 2011, 23, 1985-1992.

112 G. Kickelbick, Hybrid materials, Wiley-vch, 2007.

113 H. Xu, F. Yan, E. C. Monson and R. Kopelman, J. Biomed. Mater. Res., 2003, 66A, 870-879.

114 S. Brunauer, P. H. Emmett and E. Teller, J. Am. Chem. Soc., 1938, 60, 309-319.

115 D. Drescher, T. Buchner, D. McNaughton and J. Kneipp, Phys. Chem. Chem. Phys., 2013, 15, 5364-5373.

116 G. H. Woehrle, J. E. Hutchison and z. S. O. R. G. Finke, Turk J Chem, 2006, 30, 1-13. 